\title{
Other journals in brief
}

\section{PLAQUE MASS - COMPOSITION}

\section{Factors affecting human supragingival \\ biofilm composition. I. Plaque mass}

Haffajee AD, Teles RP et al. J Periodont Res 2008;

doi: 10.1111/j.1600-0765.2008.01154.x

:...marked variability in the total numbers of organisms on tooth surfaces in individual subjects'.

Supragingival plaque was collected from 187 adults $(4,745$ samples in total). Each sample was characterised for '40 bacterial species using checkerboard DNA-DNA hybridization'. Total counts revealed that there was marked variability in the numbers of organisms from discrete tooth surfaces. It was also found that as the total counts increased, so did the proportions of some species such as Capnocytophaga gingivalis and Eikenella corrodens whereas others such as Actinomyces naeslundii genospecies 2 and Veillonella parvula decreased. Increased counts were associated with increased pocket depth irrespective of gingival inflammation. The investigators acknowledged that 'No effort was made to take all of the supragingival plaque' from each tooth surface that was sampled and the age of the plaque biofilm was unknown.

DOI: 10.1038/sj.bdj.2009.694

\section{PLAQUE MASS - TOOTH TYPES}

\section{Factors affecting human supragingival biofilm composition. II. Tooth position \\ Haffajee AD, Teles RP et al. J Periodont Res 2008; doi: $10.1111 / j .1600-0765.2008 .01155 . x$}

\section{'composition of the supragingival biofilm was associated with} tooth location' after taking account for plaque mass.

The aim of this study was to determine if the microbial composition of supragingival plaque varied with tooth type. The plaque samples and method for microbial analysis were the same as those reported in another study (Haffajee AD, Teles RP et al. J Periodont Res 2008; doi: 10.1111/j.1600-0765.2008.01154.x). Stepwise multiple linear regression was used to look for relationships between plaque mass, bacterial species and tooth location. It was found that increased plaque mass occurred on molar and lower incisor teeth when compared with other teeth. Generally teeth with high plaque mass were associated with higher levels of certain bacterial species, although this relationship was not consistent.

\section{BODY DYSMORPHIC DISORDER}

\section{Symptoms of body dysmorphic disorder among people presenting for cosmetic dental treatment: a comparative study of cosmetic dental patients and a general population sample}

De Jongh A, Aartman IHA et al. Community Dent Oral Epidemio/ 2009. doi: 10.1111/j.1600-0528.2009.00469.x

No clear links between those who receive cosmetic dental treatment and those with BDD.

The attitudes to the overall appearance and dental appearance of 170 consecutive patients attending six different dental cosmetic clinics were ascertained by use of a questionnaire. These patients were also screened for body dysmorphic disorder (BDD). These attitudes were compared with a sample from the general population $(n=878)$. In those that had received cosmetic dentistry, there was no difference in satisfaction as to their overall appearance compared to controls. However, the authors reported that the numbers of those with BDD (using the full diagnostic screening) were significantly higher in cosmetic dental patients ( $4.2 \%$ versus $1.5 \%$ ). The authors conclude that although their "preliminary results do not raise concern about the majority of patients requesting dental care in cosmetic clinics', dentists should be aware of a possible link with BDD. DOI: 10.1038/sj.bdj.2009.696

\section{BONDING TO FLUOROSED ENAMEL}

\section{Ask the Experts. Bonding to fluorosed enamel \\ Swift EJ Jr. Oper Dent 2009; 21: 147-148}

Removal of the hypermineralised layer with a diamond bur improves the adhesion of resin composite to fluorosed enamel. Recent research has shown that the bonding of the two-step, self-etch system (Clearfil Protect Bond, Kuraray, Tokyo, Japan) to fluorosed enamel was significantly less than that to normal enamel. Grinding the enamel with a diamond bur significantly improved the adhesion to fluorosed enamel such that the bond 'was the same as that to normal enamel'. However, when using the three-step, etch-and-rinse system (OptiBond FL, Kerr, Orange, CA, USA), the effect of grinding the enamel was not as pronounced. There is some evidence that etching with phosphoric acid before application of the self-etch system adhesive and extending the etching time with the etch-andrinse adhesive can improve bond strengths.

DOI: 10.1038/sj.bdj.2009.697 